hours of the day. I often see the bottom of this dish sprinkled with seeds, evidently ejected by the birds. At present they are the seeds of the Laurustinus (Viburnum Tinus).

Rosehill, Falmouth, November 29.

HOWARI) Fox.

\section{Periodic Tides.}

ThE letter of Mr. A. S. Thompson, in your issue of December 8 , adds further interesting information as to secondary undulations, to that which I sent you in a paper printed in NATURE of February 3 last. This paper appears to have escaped Mr. Thompson's attention, as in it he will find that this subject was investigated on the Swiss Lakes by Duillier in the middle of the last century, and by Vaucher in 1804 . They found that these undulations are common to all lakes at intervals of about twenty minutes. More recent ly the subject was taken up by Mr. Napier Denison on the Great Lakes in Canada, where he found oscillations of three to four inches at intervals of from fourteen to eighteen minutes; and by $\mathrm{Mr}$. Be. Dawson during the tidal survey of the Gulf of St. Lawrence, where he found regular minor undulations occurring, in addition to those due to the tides.

W. H. WHEELER.

December Io.

\section{Cristatella Mucedo}

As this very beautiful polyzoon is generally believed to be nearly, if not quite extinct in ponds in the neighbourhood of London, I should like to record the fact that on November ig last, I took a fine specimen two inches in length, which is stil living. The colony was packed with statoblasts, most of which are now discharged. It was not perfect when taken, and has again divided since it has been in a sniall aquarium.

HENRY SCHERREN.

9 Cavendish Road, Harringay, N., December 3.

\section{The Invention of the Gimbal.}

WILl you or some of your readers kindly inform me, when and by whom the construction of the gimbal was contrived for the first time?

7 Effie Road, Walham Green, S.W. KuMAGUSU Minakata.

\section{THE VALUE OF EXERCISE.'}

$\mathrm{HE}$ value of exercise for the purpose of maintaining mens sana in corpore sano has been recognised from the remotest antiquity. Exercise, however, in its entirety seems to be divided into two sections which, though springing from the same cause, have led to different results : professionai exercise or the training and maintaining of a body of athletes, and what may perhaps best receive the name of domestic exercise. The former appears to be one of the many instances of what was originally a means of becoming an end. Professional athletics doubtless took their origin in the use of exercise as a means ; the perfect development of body and mind being the end. The huge muscles and small heads of professional athletes show us that the original means has finally become the end. This result from the point of view of the hygienist must be regarded as grotesque, and to the physician the professional athlete is neither more nor less interesting than the macrocephalic dwarf. The fainting and sickness of the over- or under-trained schoolboy, and the insomnia of the over-crammed student are essentially phenomena of the same class, and due to the same cause-viz. pathological plethora of some vascular areas, and pathological anæmia of others.

The use of exercise as a therapeutic agent, as also its use for the maintenance of health, falls under the second variety. The practice of exercises as part of one's toilette is very old. Any one conversant with the "heilgymnastik" (curative exercises) of the present day, let them belong to the systems of Ling, Schott, or

l "Respiratory Exercise in the Treatment of Disease." By Harry Campbell, M.D., B.S., F.R.C.P. Pp. viii + 200. (London: Baillière, Tindall, and $\operatorname{Cox}, \mathrm{r} 898$.)

NO. I 520 , VOL. 59]
Zander, cannot fail to be impressed with their resemblance to the devotional exercises of the devout Mahometan. Although doubtless the positions assumed by the worshipper are symbolical of passive submission, cringing obeisance, or subjected defiance, the point of interest to the physiologist is that after the performance of these devotions one experiences a distinct sense of fatigue. Thus by incorporating in his system of devotion actual muscular exercise the Prophet practically prescribed a system of "heilgymnastik," and forestalled the modern hygrienic use of exercise. It would be interesting to know to what extent the exercise part of his devotions may be modified in the case of a Mohametan with morbus cordis. One fact, as will appear from the context, is worthy of notice. The devotional exercises are all performed slowly, and the change of posture is gradual. This is doubtless from a religious standpoint reverential, but from a physiological standpoint it prevents the occurrence of breathlessness or palpitation. In the one case which I had the opportunity of observing (devotion at sunset), the respirations were accelerated by four, the pulse by sixteen per minute by the derotions. This was in Algeria, near Hammam Rhira, at an altitude of 2000 feet. This effect might, no doubt, partially be due to psychical influences.

The modern therapeutic use of exercise is mainly directed to the attainment of two objects, local or general. The local use of exercises for the strengthening of certain groups of muscles mostly interests the surgeon or the neurologist. The ingenuity of Zander in inventing machines by which almost every grnup of muscles in the body can both be exercised, and made to do an exactly graduated amount of work, has done much to develope and systematise treatment in this branch of therapeutics. In the case of all muscles, including the heart, an optimal contraction is nnly obtained when the muscle contracts against an optimal resistance. This optimal resistance varies according to the condition of the muscle. In the case of the local use of exercise it is most important at the beginning of each set of exercises to find the optimal load. The great advantage of the mechanical system of resistance exercises, as compared with the manual method, is that once this optimal load is found it can be maintained constant, or as the condition of the muscle improves can be accurately increased. From this it follows that the work done on each occasion can be measured mathematically. It is impossible to achieve this by hand.

The second object aimed at by the therapeutic use of exercise is the one of most interest to the physician, viz. the production of a general systemic effect. This effect manifests itself chiefly upon the circulatory and respiratory systems. The sweating produced by exercise, although bringing into play the secretory function of the skin, and thus causing the excretion of certain noxious substances, as well as possibly the production and addition to the blood of an internal secretion, is essentially a circulatory phenomenon, and will not be further considered here, especially as exercise is, therapeutically, rarely pushed to such an extent as to produce sweating. One of the effects of exercise upon the respiratory system is known to every one, viz. breathlessness, or an increase in the depth and frequency of the respiratory movements. This dyspnœa varies according to the condition of the patient, and the amount or rather acuteness of the exercise. Physiologists are indebted to Zuntz and Geppert (Pfugers Archives, xlii. p. 159) for having added most essentially to our knowledge of this condition. Before the work of these observers the dyspnœa attending exercise was held to be due to a diminution in the amount of oxygen and an increase in the amount of $\mathrm{CO}_{2}$ in the blood; was, in short, regarded as an asphyxia. This hypothesis was based upon the experimental results of Mathieu and Urbain ("Du Gaz du Sang," Archives de Phys., iv., I871-72). Zuntz and Geppert, however, showed 